\title{
Characterization of Legumain
}

\author{
Gerold Schwarz ${ }^{1}$, Jens Brandenburg1, \\ Michael Reich ${ }^{1}$, Timo Burster ${ }^{2}$, Christoph \\ Driessen $^{2}$ and Hubert Kalbacher ${ }^{1, *}$ \\ ${ }^{1}$ Institute of Physiological Chemistry, \\ University of Tübingen, Ob dem Himmelreich 7 , \\ D-72074 Tübingen, Germany \\ ${ }^{2}$ Department of Medicine II, University of Tübingen, \\ Otfried-Müller-Str. 10, D-72076 Tübingen, Germany \\ ${ }^{*}$ Corresponding author
}

The mammalian legumain, also called asparaginyl endopeptidase (AEP), is critically involved in the processing of bacterial antigens for MHC class II presentation. In order to investigate the substrate specificity of AEP in the P1' position, we created a peptide library and digested it with purified pig kidney AEP. Digestion was less efficient only when proline was in the P1' position. Maximum AEP activity was found in lysosomal fractions of different types of antigen presenting cells (APC). When the multiple sclerosis-associated autoantigen myelin basic protein (MBP) was digested with AEP, the immunodominant epitope 83-99 was destroyed. Myoglobin as an alternative substrate was AEP resistant. These results suggest an important, but not necessarily critical role for AEP in lysosomal antigen degradation.

Key words: Antigen processing/Cysteine

endopeptidase/Substrate specificity.

Cysteine peptidases represent one of the major groups of endocytic proteases in APC. AEP has been shown to control the processing of tetanus toxoid $C$ fragment by lysosomal extracts of human B cells (Manoury et al., 1998). Plant legumain is mainly responsible for mobilization of storage proteins and post-translational processing of seed proteins (Shutov and Vaintraub, 1987; HaraNishimura et al., 1995). It is selective for hydrolysis after asparaginyl residues, while any amino acid (aa) can occur in the $\mathrm{P} 1$ ' position without affecting substrate turnover (Ishii, 1994; Jung et al., 1998). Mammalian and plant legumain have been shown to differ in their specificity, and both in whole protein and peptide substrates not every $\mathrm{N}$-bond available is cleaved by the mammalian enzyme (Dando et al., 1999; Rotari et al., 2001). Thus additional factors must be involved in defining a substrate for mammalian AEP, one of which might be the aa in $\mathrm{P} 1$ ' position.

We here analyzed the impact of the aa in the $\mathrm{P} 1$ ' posi- tion on the turnover of a peptide library incubated with AEP, measured AEP activities in subcellular compartments of various types of APC and characterized the effect of purified AEP on three complex proteins of immunological relevance.

When we digested the peptide library ZAEN $\underline{X} A E K-\mathrm{NH}_{2}$ with AEP, 19 peptides were cleaved at similar rates in contrast to the control peptide lacking $\mathrm{N}$ in the $\mathrm{P} 1$ position. Only the peptide with proline in the $\mathrm{P} 1$ ' position was significantly less susceptible to AEP-cleavage (Figure 1). In an alternative approach we tested all these peptides in a competition assay using the fluorogenic substrate ZVAN-AMC. The control peptide ZAEQIAE-NH $\mathrm{N}_{2}$ did not compete with the degradation of the fluorogenic reporter; hence it generated maximum fluorescence $(=100 \%$ in Figure 2). Again, the proline-containing peptide was a poor substrate for AEP ( 90\% fluorescence) while all other peptides tested were more effective competitors. In detail, the cysteine-peptide competed best ( $15 \%$ fluorescence), while peptides with aspartate, glutamate and leucine at the P1' position were less effective ( $50 \%$ fluorescence), followed by methionine, glutamine, valine, tryptophan and threonine ( 40\% fluorescence). The competition of the remaining aa accounted for roughly $30 \%$ fluorescence.

To assess intact proteins of immunological relevance, we digested MBP (containing two potential cleavage sites for AEP: N84P and N92I), mutant MBP (N92 $\rightarrow$ Q92) and myoglobin with AEP (Figure 3). Consistent with our results from the peptide digestions, we only observed cleavage of wild-type MBP after N92 (creating the fragments 1-92 and 93-170), while cleavage at the N84P bond was not observed. In contrast, no cleavage after position 92 was found with mutant MBP, in agreement with the N-specificity of AEP at the P1 position. Instead, fragments 1-84 and 85-170 were generated. In general, mutant MBP was digested by AEP at a clearly reduced rate compared to the wild-type protein.

Myoglobin also contains two NX-bonds (N12V and N140D) that are potential substrates for AEP, based on our peptide digestion experiments. However, no distinct cleavage products of myoglobin were detectable, neither after $1 \mathrm{~h}$ digestion with AEP (a time when MBP was completely degraded), nor after prolonged digestion (data not shown). In contrast, digestion with the lysosomal protease cathepsin $D$ resulted in rapid degradation (in agreement with van Noort et al., 1991), ruling out that myoglobin might be protease resistant per se.

Finally, we measured AEP activities in subcellular compartments of different types of antigen presenting cells 


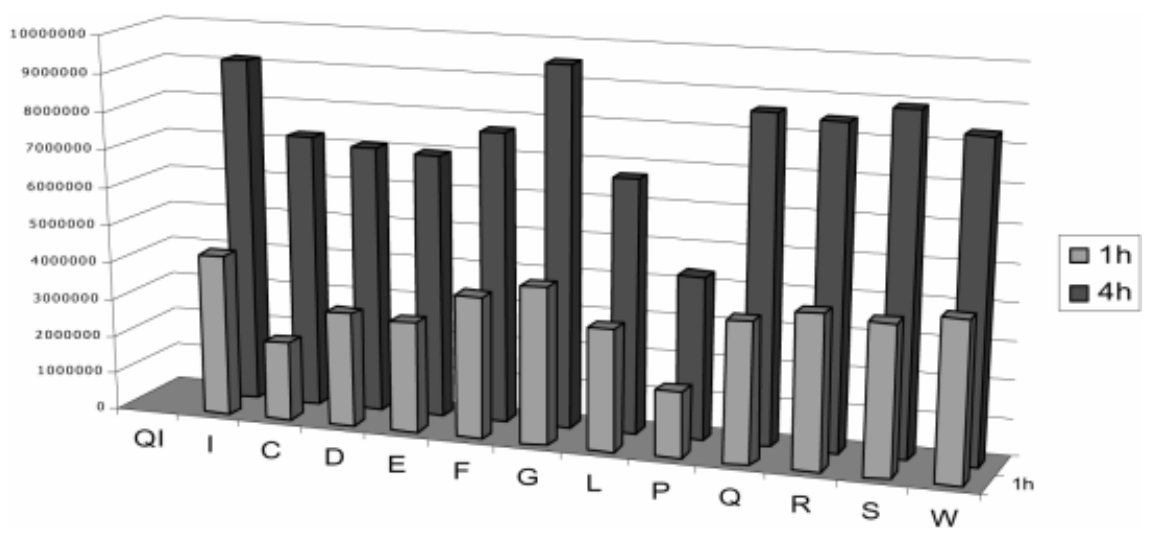

Fig. 1 Digestion of the Peptide Library ZAENXAEK-NH $\mathrm{N}_{2}(\mathrm{X}=20 \text { Different aa) and the Control Peptide (ZAEQIAE- NH})_{2}$ with AEP $($ Partially Purified According to Barrett et al., 1997) for $1 \mathrm{~h}$ and $4 \mathrm{~h}$.

The Figure shows one representative experiment with 13 selected peptides (the peptides not explicitly mentioned were digested in the same order of magnitude as the C-, D-, E- peptides; $n=3)$. Two $\mathrm{mm}$ of peptide were incubated at $37^{\circ} \mathrm{C}$ in digestion buffer $(40 \mathrm{~mm}$ citric acid, $121 \mathrm{~mm} \mathrm{Na}_{2} \mathrm{HPO}_{4}$, pH 5.8, 5 mM mercaptoethanol, 4 mм EDTA, $10 \mu \mathrm{m} \mathrm{E64,} 6 \mu \mathrm{m}$ aprotinin, 0.01\% Triton X-100) with $0.5 \mu \mathrm{l}$ AEP-extract. After 1 and 4 hours, the reaction was stopped with $0.5 \%$ TFA solution and analyzed on a RP18-column. Results are expressed as area under the curve (detection at $214 \mathrm{~nm}$ ) of the resulting digestion product ZAEN. QI represents the control peptide, letters I-W indicate the aa in P1' position. Peptides were synthesized on solid phase with the fmoc-strategy, purified by HPLC and checked by ESImass spectrometry.

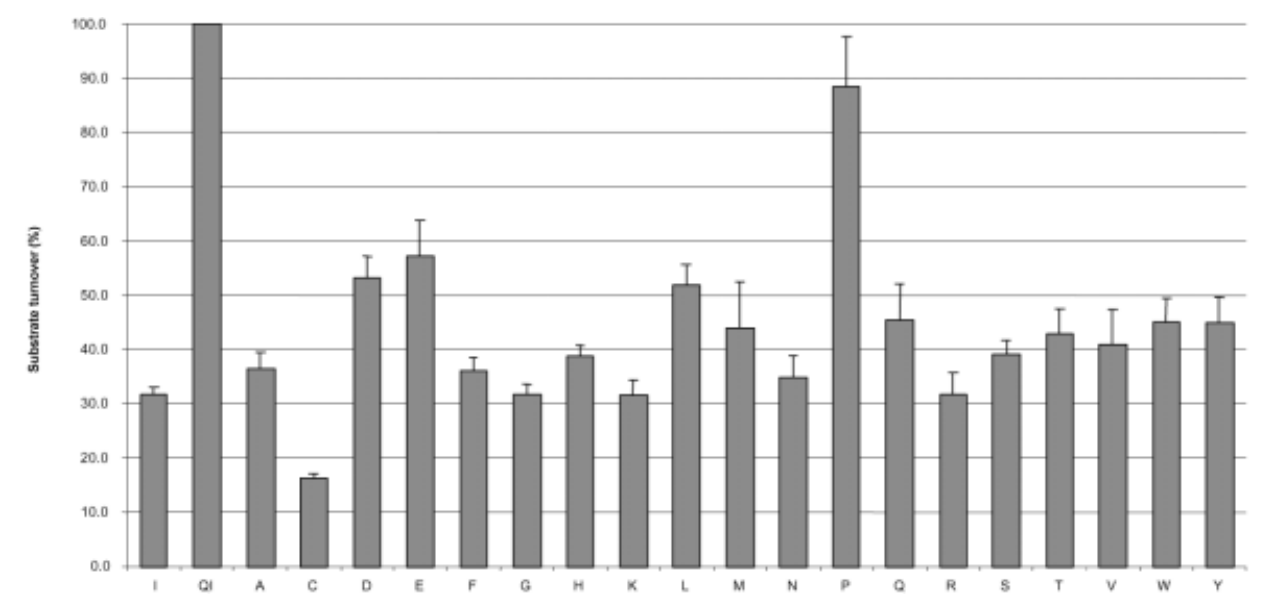

Fig. 2 Competition Assay with the Fluorogenic Substrate ZVAN-AMC.

$0.5 \mu \mathrm{l}$ of AEP was added to $2 \mathrm{~mm}$ of peptide (see Figure 1) and $45 \mu \mathrm{M}$ of ZVAN-AMC in digestion buffer (see Figure 1) and incubated at $37^{\circ} \mathrm{C}(\mathrm{n}=3)$. Liberated fluorescence was measured every 10 minutes in a fluorescence reader (Tecan SpectraFluor, $360 \mathrm{~nm}$ excitation, $465 \mathrm{~nm}$ emission) for $60 \mathrm{~min}$. The substrate turnover was determined by linear regression using 6 consecutive measurement points. Substrate turnover of the control peptide (QI, see Figure 1) was normalized to $100 \%$.

using the fluorogenic substrate ZVAN-AMC. In EBVtransformed $B$ cell lines we measured highest AEP activities in lysosomal fractions ( 1 unit). Strikingly, these activities were 10-20 times lower in lysosomal fractions of the monocytic cell line THP1. Resting dendritic cells as well as mature dendritic cells also contained significant amounts of activity in endosomal/lysosomal fractions ( 0.5 units). This suggests that AEP activity is concentrated particularly in cells specialized in antigen degradation (Figure 4).

Entirely consistent with earlier reports (Dando et al., 1999), we found a high degree of restriction of AEP for $N$ in the $\mathrm{P} 1$ position. Dando and coworkers used 12 as- paragine-containing decapeptides derived from recombinant tetanus toxoid $\mathrm{C}$ fragment (TTCF) for digestion with AEP. Ten peptides corresponding to certain sequences of the whole TTCF protein, and which contained asparagine but were not cleaved by AEP, were digested by AEP. Two decapeptides with arginine and histidine at the $\mathrm{P} 1$ ' position remained resistant to AEP (Dando et al., 1999). In contrast, our experiments with two independent methods demonstrated no resistance of any of our 20 peptides (ZAEN $\underline{X} A E K-\mathrm{NH}_{2}$ ) to AEP cleavage. Indeed, as shown in Figure 1 and 2, the peptides with arginine and histidine at the $\mathrm{P} 1$ ' position were good substrates for AEP.

The question arises why are not all NX-bonds available 
for becoming substrates of AEP in whole proteins? Additional factors seem to be necessary to define AEP cleavage sites and obviously the structural conformation of the protein is likely to be critical.
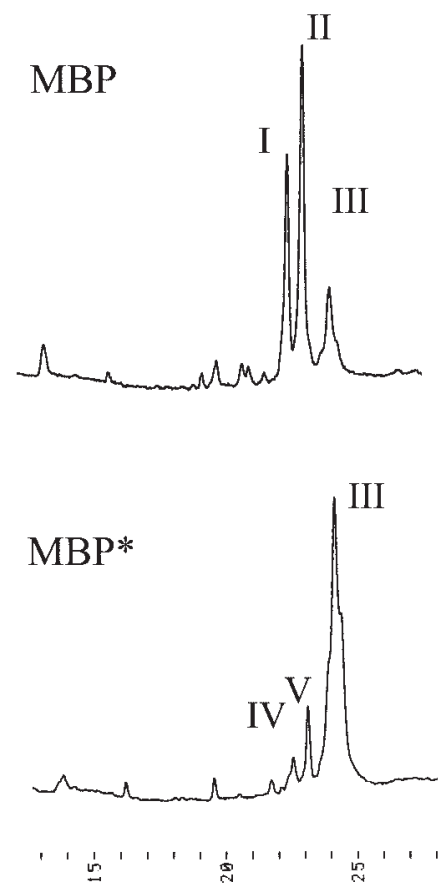

Fig. 3 HPLC of MBP and Mutant MBP $\left(M^{*} P^{\star}\right)$ after $1 \mathrm{~h}$ Digestion.

$\mathrm{MBP}$ and $\mathrm{MBP}^{*}$ were digested with $0.1 \mu \mathrm{l}$ AEP (detection at $214 \mathrm{~nm}$ ). Both proteins were expressed in $E$. coli and purified by HPLC. Digestions were performed in $0.25 \mathrm{M}$ citrate buffer, $\mathrm{pH} 5.4$ (2.5 mM DTT) using $2 \mu \mathrm{g}$ of substrate. The fragments indicated are: I = fragment $93-170, \mathrm{II}=1-92, \mathrm{III}=$ intact $\mathrm{MBP} / \mathrm{MBP}^{*}$ $1-170$, IV = fragment $1-84, \mathrm{~V}=$ fragment $85-170$. Fragments were identified by MALDI-mass spectrometry.
The initial proteolytic steps in antigen processing are of major importance, because they determine the set of peptides that can be generated as processing proceeds. AEP has been shown to mediate such initial unlocking of a protein antigen (Manoury et al., 1998). By eliminating the three major AEP-processing sites in TTCF, Antoniou et al. (2000) demonstrated that the protein is highly resistant to proteolysis by AEP and crude lysosomal extracts and is dramatically impaired in its ability to be processed and presented to T cells. At an early stage of antigen processing, a limited set of processing intermediates might be generated by a single protease that should have a well-balanced substrate specificity. While some degree of specificity is needed to ensure that only a limited number of sufficiently stable proteolytic fragments is generated, a certain degree of stochastic cleavage is required so that most protein antigens can successfully be attacked. According to our results, AEP is well suited for this task. It generates two stable proteolytic fragments from the autoantigen MBP, that can serve as substrates for further processing. AEP combines a narrow substrate specificity in the $\mathrm{P} 1$ position with almost no restriction at P1', in contrast to cathepsins, for example. The fact that high AEP activities are measured in highly specialized antigen presenting cells corroborates the key role of AEP in antigen processing. However, as we have also demonstrated, myoglobin, another immunologically relevant protein, is entirely resistant to AEP. A recent study showed a rapid degradation of the model protein hen egg lysozyme in B cells without discrete detectable processing intermediates, thereby demonstrating no requirement for initial unlocking of this protein (Plüger et al., 2002). It remains to be determined whether initial unlocking of proteins by AEP is a general rule or the exception in $\mathrm{MHC}$ class II-dependent antigen processing.

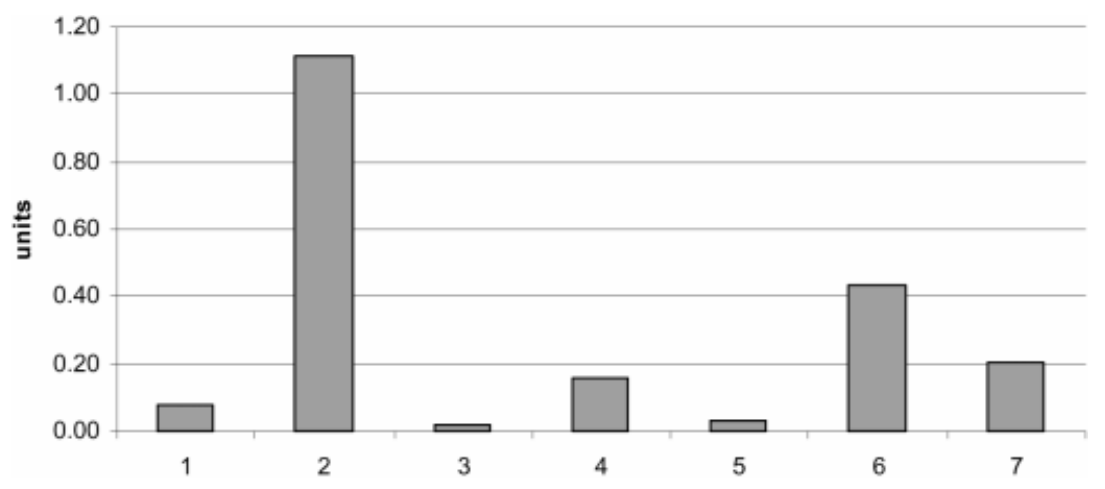

Fig. 4 AEP Activities in Endocytic Fractions of Antigen Presenting Cells.

Fifty $\mu \mathrm{M}$ ZVAN-AMC were incubated with $130 \mu \mathrm{l}$ reaction buffer (see Figure 1) and with $1-5 \mu \mathrm{g}$ protein of enriched endocytic compartments (Schröter et al., 1999) and measured in a fluorescence reader (Tecan SpectraFluor, $360 \mathrm{~nm}$ excitation, $465 \mathrm{~nm}$ emission). The assay contained E64, aprotinin and EDTA to largely exclude proteases other than AEP. As specificity controls, each experiment was performed in duplicate, with or without addition of the competitive AEP inhibitor ZAENK (Manoury et al., 1998). The amount of substrate turnover that could be blocked by ZAENK was considered specific AEP activity. Specific AEP activity could be eliminated by addition of iodoacetamide to the reaction. One unit $=1 \mu \mathrm{mol} \times \mathrm{min}^{-1} \times \mathrm{g}^{-1}$ protein. 1: endosomal fraction of COX; 2: lysosomal fraction of COX; 3 : endosomal fraction of WT51; 4: lysosomal fraction of WT51; 5 : lysosomal fraction of THP1; 6: endosomal/lysosomal fraction of resting dendritic cells; 7: endosomal/lysosomal fraction of mature dendritic cells. COX and WT51 are EBV-transformed B cell lines. THP1 is a monocytic cell line. Monocyte-derived dendritic cells were generated from PBMC using GM-CSF and IL4 and matured with TNF $\alpha$. 


\section{Acknowledgement}

This work was supported by the SFB 510 of the Deutsche Forschungsgemeinschaft.

\section{References}

Antoniou, A.N., Blackwood, S.L., Mazzeo, D., and Watts, C. (2000). Control of antigen presentation by a single protease cleavage site. Immunity 12, $391-398$.

Chen, J.M., Dando, P.M., Rawlings, N.D., Brown, M.A., Young, N.E., Stevens, R.A., Hewitt, E., Watts, C., and Barrett A.J. (1997). Cloning, isolation and characterization of mammalian legumain, an asparaginyl endopeptidase. J. Biol. Chem. 272, $8090-8098$.

Choi, S.J., Reddy, S.V., Devlin, R.D., Menaa, C., Chung, H., Boyce, B.F., and Roodman, G.D. (1999). Identification of human asparaginyl endopeptidase (legumain) as an inhibitor of osteoclast formation and bone resorption. J. Biol. Chem. 274, $27747-27753$

Dando, P.M., Fortunato, M., Smith, L., Knight, C.G., McKendrick, J.E., and Barrett, A.J. (1999). Pig kidney legumain: an asparaginyl endopeptidase with restricted specificity. Biochem. J. 339, $743-749$.

Hara-Nishimura, I., Shimada, T., Hiraiwa, N., and Nishimura, M. (1995). Vacuolar processing enzyme responsible for maturation of seed proteins. J. Plant Physiol. 145, 632-640.

Ishii, S.I. (1994). Legumain: asparaginyl endopeptidase. Methods Enzymol. 244, 604-615.
Jung, R., Scott, M.P., Nam, Y.W., Beaman, T.W., Bassuner, R., Saalbach, I., Muntz, K., and Nielsen, N.C., (1998). The role of proteolysis in the processing and assembly of 11 s seed globulins. Plant Cell 10, 343-357.

Manoury, B., Hewitt, E., Morrice, N., Dando, P.M., Barrett A.J., and Watts, C. (1998). An asparaginyl endopeptidase processes a microbial antigen for class II MHC presentation. Nature 396, $695-699$.

Plüger, E.B.E., Boes, M., Alfonso, C., Schröter, C.J., Kalbacher, H., Ploegh, H.L., and Driessen, C. (2002). Specific role for cathepsin $\mathrm{S}$ in the generation of antigenic peptides in vivo. Eur. J. Immunol. 32, 467-476.

Rotari, V.I., Dando, P.M., and Barrett, A.J. (2001). Legumain forms from plants and animals differ in their specificity. Biol. Chem. 382 , 953-959.

Schröter, C.J., Braun, M., Englert, J., Beck, H., Schmid, H. and Kalbacher, H. (1999). A rapid method to separate endosomes from lysosomal contents using differential centrifugation and hypotonic lysis of lysosomes. J. Immunol. Methods 227, $161-168$

Shutov, A.D., and Vaintraub, I.A. (1987). Degradation of storage proteins in germinating seeds. Phytochemistry 26, $1557-$ 1566.

Van Noort, J.M., Boon, J., Van der Drift, A.C.M., Wagenaar, J.P.A., Boots, A.M.H., and Boog, J.P.G. (1991). Antigen processing by endosomal proteases determines which sites of sperm-whale myoglobin are eventually recognized by $\mathrm{T}$ cells. Eur. J. Immunol. 21, 1989-1996.

Received January 16, 2002; accepted March 11, 2002 